Published in final edited form as:

Chembiochem. 2020 February 03; 21(3): 310-314. doi:10.1002/cbic.201900391.

\title{
Genetic encoding of a bioconjugation handle for [2+2+2] cycloaddition reactions
}

\author{
Christopher R. Travis, Gillian H. Gaunt, Elizabeth A. King, Douglas D. Young \\ Department of Chemistry, College of William \& Mary, PO Box 8795, Williamsburg, VA, 23187 \\ USA
}

\begin{abstract}
Protein bioconjugates have many critical applications, especially in the development of therapeutics. Consequently, the design of novel methodologies to prepare protein bioconjugates is of great importance. Herein, we present the development and optimization of a novel strategy to prepare bioconjugates via a genetically encoded $[2+2+2]$ cycloaddition reaction. To do this, a novel unnatural amino acid (UAA) containing a dipropargyl amine functionality was synthesized and incorporated site-specifically. This UAA-containing protein was reacted with an alkynecontaining fluorophore to afford a covalently-linked, well-defined protein bioconjugate. This reaction is convenient with an optimized reaction time of just 2 hours at room temperature and yields a stable, polysubstituted benzene ring. Overall, this work contributes a new bioconjugation strategy to the growing toolbox of reactions to develop protein bioconjugates, which have a myriad of applications.
\end{abstract}

\section{Graphical Abstract}

A new unnatural amino acid has been synthesized and genetically encoded into a protein. This functionality facilitated the development of a novel $[2+2+2]$ cycloaddition bioconjugation, as well as its use in previously developed conjugation reactions.

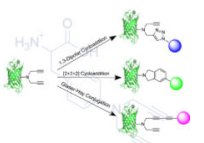

\section{Keywords}

bioconjutation; unnatural amino acid; cycloaddition; alkyne

Bioconjugation reactions, in which a biomacromolecule is covalently linked to a functional partner, are presently widely employed in the fields of medicine, pharmaceuticals, and materials. ${ }^{[1,2]}$ Protein bioconjugates, particularly those in which an antibody is conjugated to a potent small-molecule drug, are especially valuable for drug delivery. The attachment of an antibody allows for the drug molecule to be targeted to a specific location within the

dyoung01@wm.edu.

Supporting information for this article is given via a link at the end of the document. 
patient, making it more effective in interacting with the target and preventing off-target effects. Thus, conjugation to an antibody allows lower doses of the drug to be employed to achieve efficacy in patients. Ultimately, lower doses can lead to reduced side effects in patients, particularly for treatments such as chemotherapy for cancer. ${ }^{[3,4]}$

Unnatural amino acid (UAA) technology represents a means to utilize bioorthogonal handles to prepare well-defined, homogeneous protein bioconjugate products. These homogeneous conjugates have been shown to be more efficacious than heterogeneous conjugates and to possess several therapeutic advantages. ${ }^{[2,5,6]}$ One common bioorthogonal reaction employed to prepare protein bioconjugates is the copper-catalyzed azide alkyne cycloaddition (CuAAC), known as the "copper click" reaction, in which an UAA with either an alkyne or azide group is reacted with an azide-containing or alkyne-containing reaction partner, respectively. ${ }^{[2,6]}$ More recently, we reported the development of a Glaser-Hay bioconjugation reaction involving the coupling of an alkynyl UAA with a soluble terminal alkyne to afford a covalent diyne linkage. ${ }^{[7-10]}$ However, there are a limited number of bioconjugation reactions available, as they necessitate physiological conditions and must lack cross-reactivity with endogenous biological systems. ${ }^{[4]}$ Thus, it is critical to develop novel bioconjugation reactions to expand their scope and afford a variety of chemical tools for different applications.

The $[2+2+2]$ cyclotrimerization reaction can be catalyzed by a variety of transition metals and relies on three alkyne moieties reacting to yield aromatic compounds (Figure 1A). ${ }^{[1]}$ This cycloaddition is widely used as a key organic methodology to generate stable, polysubstituted benzene rings in an atom-efficient manner. ${ }^{[12]}$ To the best of our knowledge, a biological $[2+2+2]$ cyclotrimerization has not previously been reported, despite the prominence of this reaction in organic synthesis. Recently, Wang et al. demonstrated the utilization of a rhodium-catalyzed cyclotrimerization in aqueous conditions at $60{ }^{\circ} \mathrm{C}$, illustrating the potential feasibility of this reaction in physiological environments (Supporting Information). ${ }^{[13]}$ Consequently, we aimed to adapt this reaction for use on biological macromolecules to afford a novel bioconjugation reaction. Ideally, we aimed to contribute a new bioorthogonal reaction to the biological toolbox as a means to assist in disease diagnosis and improve drug delivery systems. Herein, we report a novel cyclotrimerization bioconjugation utilizing a newly synthesized and site-specifically incorporated dipropargyl amine UAA. This work has key applications towards the preparation of specific, homogeneous protein bioconjugates.

Given the aqueous $[2+2+2]$ cycloaddition previously reported, we sought to optimize this reaction at temperatures lower than $60{ }^{\circ} \mathrm{C}$ using a water-soluble carboxylated biphenyl ligand, which has previously been demonstrated to provide effective chelation in the GlaserHay bioconjugation. ${ }^{[8]}$ As a proof-of-concept experiment, we successfully trimerized propargyl ether at room temperature under similar cyclotrimerization conditions as previously reported (Supporting Information).

In order for this reaction to be applicable to a protein context, a dipropargyl functionality must be included into the unnatural amino acid component. Thus, a UAA containing the dipropargyl amine functionality on a substituted phenylalanine backbone, $p \operatorname{DPrAF}(\mathbf{1})$, was 
synthesized (Figure 1B; Supporting Information). To prepare 1, a commercially available Boc-protected 4-aminophenylalanine was reacted with an excess of propargyl bromide in the presence of excess potassium carbonate. While some mono-addition of a single propargyl group to the amine was observed, the majority of product obtained contained the addition of three propargyl groups, two on the amine and one on the carboxylic acid in the amino acid backbone. Following previously reported deprotection procedures, $\mathbf{1}$ was prepared with an overall yield of $47 \%{ }^{[8]}$

Following the synthesis of $\mathbf{1}$, the next requisite for site specific incorporation is the genetic encoding of the new UAA. While this typically requires a double-sieve aminoacyl-tRNA synthetase (aaRS) selection, previous research has demonstrated that several pre-existing aaRS/tRNA pairs confer a degree of polyspecificity towards multiple UAAs. Consequently, we attempted to identify an appropriate aaRS capable of both recognizing $\mathbf{1}$ and charging it to the appropriate tRNA. We first investigated several synthetases due to either known polyspecificity, or due to their incorporation of structurally similar UAAs. ${ }^{[14]}$ Plasmids encoding both the aaRS and tRNA were co-transformed into BL21(DE3) E. coli with a pETGFP-TAG-151 plasmid, harboring GFP with a TAG codon at position 151. Following protein expression, GFP mutants were purified using a Ni-NTA resin and analyzed by SDSPAGE to determine incorporation of $\mathbf{1}$. Gratifyingly, the promiscuous $p \mathrm{CNF}$ aaRS was shown to effectively incorporate $\mathbf{1}$ into GFP at position 151, in similar yields to its incorporation of $p \mathrm{PrF}$ and $p \mathrm{BrPrF}$, two commonly employed alkyne-containing UAAs (Figure 1C). Successful incorporation was also confirmed through mass spectrometry (Supporting Information).

With 1 successfully encoded into a protein, optimization of the [2+2+2] cyclotrimerization in a biological context was investigated. As is the case in other bioconjugations, the amount of transition metal catalyst should be minimized to reduce potential cytotoxicity. Conveniently, the toxicity of rhodium has been demonstrated to be lower than that of other transition metals, including platinum, palladium, cadmium, nickel and chromium. ${ }^{[15]}$ More specifically, in assays examining the impact of transition metals on oxidative damage in epithelial cells, rhodium was demonstrated to be the least cytotoxic of the metals tested. Further, rhodium complexes have also been integrated into proteins to generate stable organometallic proteins. ${ }^{[16]}$ Thus, it is reasonable to use rhodium in bioconjugation reactions, provided low concentrations and relatively short reaction times are employed.

To test the viability of this reaction, we sought to couple the $p$ DPrAF containing GFP with the commercially available Fluor 488-Alkyne (Figure 2A). To do this, a rhodium (I) dimer complex, $[\mathrm{Rh}(\mathrm{cod}) \mathrm{Cl}]_{2}(250 \mathrm{mM}$ in DMSO), was mixed with a di-carboxylated biphenyl ligand $\left(500 \mathrm{mM}\right.$ in $\mathrm{H}_{2} \mathrm{O}$ ). Following catalyst complex formation, the $p$ PPrAF-GFP $(\mathrm{pH}=$ 7.4, $\sim 1.0 \mathrm{~g} / \mathrm{mL}$ ) and Fluor 488-Alkyne (1 $\mathrm{mM}$ in DMSO) were added. This aqueous reaction proceeded for 12 hours at $4{ }^{\circ} \mathrm{C}$. A lower temperature than in the organic test of this aqueous coupling was employed in an attempt to limit protein degradation caused by rhodium. Gratifyingly, the reaction was successful, as indicated by fluorescence at the appropriate molecular weight by SDS-PAGE analysis (Figure 2B). As the GFP was denatured prior to the gel, the fluorescent signal is the result of a direct conjugation between the protein and the fluorophore. Successful bioconjugation through a $[2+2+2]$ cycloaddition reaction was also 
confirmed through mass spectrometry (Supporting Information). Unfortunately, in initial reactions, significant levels of protein degradation were also observed, requiring further optimization of reaction conditions.

It was hypothesized that the observed protein degradation was potentially due to the formation of radicals generated by the rhodium. This hypothesis is based on previous observations of protein oxidation during the Glaser-Hay bioconjugation due to the presence of a copper catalyst. ${ }^{[7,8]}$ In order to mitigate radical formation, catalase and sodium ascorbate were examined as radical scavengers to reduce protein oxidation and minimize protein degradation. The utilization of catalase was previously demonstrated to be successful in the case of the Glaser-Hay reaction. ${ }^{[9]}$ Moreover, sodium ascorbate has a long history of reducing protein oxidation in bioconjugation reactions, namely in copper click reactions and in biological Sonogashira couplings. ${ }^{[17]}$ Biological cyclotrimerization reactions between $p \mathrm{DPrAF}$ and Fluor 488-Alkyne were attempted under the previously described conditions, but with added catalase or sodium ascorbate. Both catalase and sodium ascorbate resulted in significantly reduced protein degradation during the $[2+2+2]$ cycloaddition bioconjugation, with the latter being most effective, suggesting that damaging radicals are likely formed at some point during the reaction. Overall, we successfully performed a novel bioconjugation reaction between GFP harboring 1 at residue 151 and Fluor 488-Alkyne through a [2+2+2] cyclotrimerization.

While the addition of sodium ascorbate successfully reduced protein degradation, further optimization of the reaction was carried out, as some degradation was still observed.

Initially, a time course was conducted to elucidate the optimal reaction time. Reactions were conducted for durations of $0,2,4,8$, and 12 hours with all other conditions kept constant. It was determined that protein degradation increased fairly linearly with time, and the maximum ratio of coupling to form the bioconjugate product occurred after a reaction time of 2 hours (Figure 3A; Supporting Information). The ratio of coupling was determined by comparing the densiometry of the fluorescent signal to the Coomassie stain, and normalizing to overall protein levels between replicates. Interestingly, in each of the two trials, we observed a higher ratio of coupling in the 12 hour reaction relative to the 8 hour reaction., and additional replicates yielded the same ratios. We hypothesize that these results are due to decay of the rhodium complex after around 8 hours, resulting in no additional protein degradation, but continued cycloaddition of alkynes which have already been activated. Further studies are needed to test this hypothesis. We next investigated the effects of temperature on the reaction, evaluating reaction temperatures of $4{ }^{\circ} \mathrm{C}, 22{ }^{\circ} \mathrm{C}$, and $37{ }^{\circ} \mathrm{C}$. These reactions were conducted for 2 hours with all other conditions held constant. It was observed that the $22{ }^{\circ} \mathrm{C}$ reaction afforded the best coupling relative to protein degradation. Reaction at $37^{\circ} \mathrm{C}$ led to significant protein degradation and reduced coupling ratios, while reactions at $4{ }^{\circ} \mathrm{C}$ had very little protein degradation, but lower coupling ratios than reactions at $22{ }^{\circ} \mathrm{C}$ (Figure 3B; Supporting Information). Finally, we examined the effect of $\mathrm{pH}$ on the reaction. In the original proof of concept, GFP harboring $\mathbf{1}$ in a phosphate-buffer solution with $\mathrm{pH} 7.4$ was employed. Consequently, the cyclotrimerization reaction was conducted for 2 hours at $22{ }^{\circ} \mathrm{C}$ on reactions containing protein in solutions of $\mathrm{pH} 6.0, \mathrm{pH} 7.4$, and $\mathrm{pH}$ 8.0. While $\mathrm{pH}$ did not appear to have any effect on coupling, it did have a minor impact on 
protein degradation, with the $\mathrm{pH} 7.4$ reaction affording the least protein degradation (Supporting Information).

With the optimized conditions established, the coupling yield was determined via the coupling of the GFP to a SR-Fluor 680 -Alkyne $\left(\varepsilon=257,800 \mathrm{M}^{-1} \mathrm{~cm}^{-1}\right)$. The unique spectrum of this alkyne fluorophore relative to GFP allowed for quantification of the coupling yield via absorption spectroscopy. Using the absorbance at $\lambda_{\max }$ and extinction coefficients of both the GFP and the alkynyl fluorophore, Beer's law was employed to demonstrate a $91 \%$ coupling yield for this $[2+2+2]$ cycloaddition bioconjugation reaction under these optimized conditions. No SR-Fluor 680 absorbance was detected in comparable conditions with rhodium omitted from the reaction. While the coupling efficiency was high, future optimization may be necessary to further increase efficiency and decrease protein degradation.

The genetic incorporation of $\mathbf{1}$ as a bioconjugation handle is also advantageous due to its applicability in a range of bioconjugation reactions. Beyond just the $[2+2+2]$ cycloaddition, the alkynyl functionalities can also be employed in other reactions. Specifically, the versatility of the UAA 1 was assessed through examining its reactivity in an alkyne/azide 1,3-dipolar cycloaddition ("copper click") bioconjugation, as well as in a Glaser-Hay bioconjugation. For the copper click bioconjugation, the terminal alkyne groups of $\mathbf{1}$ within GFP were reacted with an azide-containing fluorophore to form a stable triazole ring. For the Glaser-Hay bioconjugation, the terminal alkyne group in $\mathbf{1}$ in GFP was reacted with an alkyne-containing fluorophore in the presence of a $\mathrm{Cu}(\mathrm{I}) / \mathrm{TMEDA}$ catalyst to generate a linear, stable 1,3-diyne functional group. For each, we also hypothesized that these reactions could occur on both terminal alkynes within the same protein, which would afford a bioconjugate with two fluorophores attached to GFP at position 151. Gratifyingly, SDSPAGE demonstrated that $\mathbf{1}$ incorporated into proteins is capable of being employed in both copper click and Glaser-Hay bioconjugations (Figure 4). Analysis by MS indicated the single addition of a fluorophore for both the Glaser-Hay and 1,3-dipolar cycloaddition reactions under these conditions, as well as some double-addition of the fluorophore through the copper click reaction (Supporting Information). Despite the possibility for two additions due to the presence of two alkyne moieties in the $p$ DPrAF, multi-addition products were not the major products obtained. Further optimization of these reactions could afford conditions more favorable for the secondary addition of the fluorophore. Combined with its use in our newly developed cyclotrimerization bioconjugation, there are at least three unique bioconjugation reactions in which $p$ DPrAF can participate, making it a valuable amino acid with many potential applications.

Overall, the synthesis and incorporation of a novel, dipropargyl amine UAA capable of undergoing both the alkyne/azide 1,3-dipolar cycloaddition and Glaser-Hay bioconjugations was demonstrated. Further, this novel UAA was utilized in a novel [2+2+2] cyclotrimerization bioconjugation. This bioconjugation affords a polysubstituted benzene ring as part of the conjugate, generating a highly stable covalent linkage between the two reaction partners. While potential further optimization of the reaction is being investigated, this work introduces a new bioconjugation reaction as a biochemical tool with widespread utility in a plethora of applications. 


\section{Experimental Section}

\section{Synthesis of $p$-dipropargylaminophenylalanine (pDPrAF).}

Boc- $p$-Aminophenylalanine $(0.50 \mathrm{~g}, 1 \mathrm{eq}, 1.78 \mathrm{mmol})$ was added to a flame-dried vial.

Potassium carbonate $(1.23 \mathrm{~g}, 5 \mathrm{eq}, 8.92 \mathrm{mmol})$ was added, followed by DMF $(7.0 \mathrm{~mL})$. This mixture was stirred at room temperature for 5 minutes. Propargyl bromide $(0.78 \mathrm{~mL}, 5 \mathrm{eq}$, $8.92 \mathrm{mmol}$ ) was then introduced and the reaction was stirred at $80^{\circ} \mathrm{C}$ for 96 hours. The reaction was cooled to room temperature and extracted with DCM and brine. The organic layers were combined, dried with magnesium sulfate, filtered, and excess solvent was removed in vacuo. The reaction was purified via flash chromatography (silica gel, 3:1 hexanes:ethyl acetate) to yield the desired product as a yellow oil $(0.337 \mathrm{~g}, 0.855 \mathrm{mmol}$, 47.9\% yield). ${ }^{1} \mathrm{H}$ NMR (400 MHz, $\mathrm{CDCl}_{3}$ ): $\delta 7.06$ (d, J = $9 \mathrm{~Hz}, 2 \mathrm{H}$ ), 6.87 (d, J = $9 \mathrm{~Hz}, 2$ H), $4.96(\mathrm{~d}, \mathrm{~J}=8 \mathrm{~Hz}, 1 \mathrm{H}), 4.70$ (q, J = $18 \mathrm{~Hz}, 2 \mathrm{H}), 4.56$ (d, J = $8 \mathrm{~Hz}, 1 \mathrm{H}), 4.08$ (s, $4 \mathrm{H})$, 3.02 (t, J = 8 Hz, $2 \mathrm{H}), 2.51$ (s, $1 \mathrm{H}), 2.24$ (s, $2 \mathrm{H}), 1.41$ (s, $9 \mathrm{H}) .{ }^{13} \mathrm{C} \mathrm{NMR}(400 \mathrm{MHz}$, $\left.\mathrm{CDCl}_{3}\right): \delta 171.4,155.3,147.0,130.3,126.8,115.9,80.1,79.4,75.6,72.9,54.5,52.7,40.6$, 37.2, 28.5. $\mathrm{M} / \mathrm{Z}=395.3$. This product was then dissolved in 1,4-dioxane $(2 \mathrm{~mL})$ followed by aqueous $1 \mathrm{M}$ lithium hydroxide $(2 \mathrm{~mL})$, and the reaction was stirred at room temperature for 2 hours. The 1,4-dioxane was then removed in vacuo and the resulting aqueous solution was acidified through the dropwise addition of $6 \mathrm{M} \mathrm{HCl}$. The reaction was then extracted into ethyl acetate and the organic layer dried with magnesium sulfate and filtered. Excess solvent was removed in vacuo to yield a light brown oil. This oil was dissolved in DCM (1.5 mL). Trifluoroacetic acid (TFA, $0.5 \mathrm{~mL}$ ) was added and the reaction was stirred at room temperature for 1 hour. Excess solvent was removed in vacuo to yield $p \mathrm{DPrAF}$ as a brown solid (0.215 g, $0.840 \mathrm{mmol}, 98 \%$ yield). ${ }^{1} \mathrm{H}$ NMR (400 MHz, MeOD): $\delta 7.18$ (d, J = $9 \mathrm{~Hz}, 2$ H), 6.98 (d, J = 9 Hz, 2 H), 4.13 (s, 4 H), 3.30 (s, 1 H), 3.24 (dd, J = 9 Hz, 1 H), 3.07 (dd, J = $9 \mathrm{~Hz}, 1 \mathrm{H}$ ), 2.58 (s, $2 \mathrm{H}) .{ }^{13} \mathrm{C}$ NMR (400 MHz, MeOD): $\delta$ 170.2,147.6, 129.9, 124.6, 116.0, 78.9, 72.7, 54.1 39.8, 35.3. $\mathrm{M} / \mathrm{Z}=257.1$. Overall yield $=47.1 \%$.

\section{Expression of $p$ DPrAF-containing GFP-151.}

Escherichia coli BL21(DE3) cells were co-transformed with a pET-GFP-TAG-151 plasmid $(2.0 \mu \mathrm{L})$ and a pEvol- $p \mathrm{CNF}$ plasmid $(2.0 \mu \mathrm{L})$ using an Eppendorf electroporator. Cells were then plated on LB-agar plates supplemented with ampicillin $(50 \mathrm{mg} / \mathrm{mL})$ and chloramphenicol $(34 \mathrm{mg} / \mathrm{mL})$ and grown at $37{ }^{\circ} \mathrm{C}$. After 16 hours, a single colony was used to inoculate $\mathrm{LB}$ media $(10 \mathrm{~mL})$ supplemented with ampicillin and chloramphenicol. The culture was grown to confluence at $37^{\circ} \mathrm{C}$ over 16 hours. This culture was then used to begin an expression culture in $\mathrm{LB}$ media $(20 \mathrm{~mL})$ at $\mathrm{OD}_{600}=0.1$, then incubated at $37^{\circ} \mathrm{C}$ until it reached an $\mathrm{OD}_{600}$ of between 0.7 and 0.8 . At this point, mutant protein expression was induced through the addition of $1 \mathrm{M} \mathrm{ITPG}(20 \mu \mathrm{L})$ and $20 \%$ arabinose $(20 \mu \mathrm{L})$, as well as $100 \mathrm{mM} p \operatorname{DPrAF}(200 \mu \mathrm{L})$. Induced cells were grown for an additional 16 hours at $30^{\circ} \mathrm{C}$, then harvested via centrifugation (10 mins, $5000 \mathrm{rpm}$ ). The media was decanted, and the cell pellet was stored in a $-80^{\circ} \mathrm{C}$ freezer for 20 minutes. Mutant GFP was then purified using commercially available Ni-NTA spin columns according to the manufacturer's protocol. Protein yield and purity was then assessed via SDS-PAGE and spectrophotometrically via a Nanodrop spectrophotometer. Protein was then transferred into phosphate buffered saline (PBS) solution using 10k MWCO spin columns prior to use in bioconjugation reactions. 


\section{Biological cyclotrimerization protocol.}

To a sterile $1.5 \mathrm{~mL}$ Eppendorf tube, the following were added: $5 \mu \mathrm{L}$ of $[\mathrm{Rh}(\operatorname{cod}) \mathrm{Cl}]_{2}(250$ $\mathrm{mM}$ in DMSO) and $5 \mu \mathrm{L}$ of 2,2'-Bipyridine-4,4'-dicarboxylic acid (500 $\mathrm{mM}$ in $\mathrm{DI} \mathrm{H}_{2} \mathrm{O}$ ). The two solutions were mixed thoroughly by pipetting until a dark red color was achieved. Next, $30 \mu \mathrm{L}$ of GFP containing $p \mathrm{DPrAF}$ at position 151 (GFP/ $p \mathrm{DPrAF} ; \mathrm{pH}=7.4 ; \sim 1.0$ $\mathrm{mg} / \mathrm{mL}$ ) and $20 \mu \mathrm{L}$ of Fluor 488-Alkyne ( $1 \mathrm{mM}$ in DMSO) were added to the tube. Finally, 5 $\mu \mathrm{L}$ of sodium $\mathrm{L}$-ascorbate $\left(200 \mathrm{mM}\right.$ in $\left.\mathrm{DI} \mathrm{H}_{2} \mathrm{O}\right)$ was added to the tube. The reaction was incubated at $22{ }^{\circ} \mathrm{C}$. After 2 hours, excess reactants were removed via buffer exchange using 10k MWCO spin columns. The reaction was washed with phosphate buffered saline solution $(\mathrm{pH}$ 7.4 PBS, $8 \times 200 \mu \mathrm{L}$ ) and concentrated to a final volume of $50 \mu \mathrm{L}$. The reaction was analyzed by SDS-PAGE and imaged using a SYPRO Ruby scan to analyze fluorescence. The gel was stained for 3 hours using Coomassie Brilliant Blue, then destained overnight using a methanol solution (60\% deionized water, $30 \%$ methanol, $10 \%$ glacial acetic acid). The gel was then imaged using a Coomassie scan protocol.

\section{Supplementary Material}

Refer to Web version on PubMed Central for supplementary material.

\section{Acknowledgements}

CRT would like to acknowledge support from the Arnold and Mabel Beckman Foundation through the Beckman Scholars Program. DDY would like to acknowledge funding from the National Institute of General Medical Sciences of the NIH (R15GM113203) and the Camille and Henry Dreyfus Foundation (TH-17-020). We would like to thank Prof. Peter Schultz for providing the pEvol plasmids employed in this study. We would also like to thank Prof. Abhishek Chatterjee and Prof. John Poutsma for assistance with mass spectrometry experiments.

\section{References}

[1]. a)Kalia J, Raines R, Curr Org Chem 2010, 14(2), 138-147; [PubMed: 20622973] b)Hermanson GT, Bioconjugate techniques, Academic Press London UK, 3rd ed 1996.;c)Lang K, Chin JW, Chem Rev 2014, 114(9), 4764-4806; [PubMed: 24655057] d)Ning X, Guo J, Wolfert MA, Boons GJ, Angew Chem Int Ed Engl 2008, 47(12), 2253-2255; [PubMed: 18275058] e)Link AJ, Mock ML, Tirrell DA, Curr Opin Biotechnol 2003, 14(6), 603-609; [PubMed: 14662389] f)Wang Q, Chan TR, Hilgraf R, Fokin VV, Sharpless KB, Finn MG, J Am Chem Soc 2003, 125(11), 3192-3193; [PubMed: 12630856] g)Kim CH, Axup JY, Schultz PG, Curr Opin Chem Biol 2013, 17(3), 412-419; [PubMed: 23664497] h)Sletten EM, Bertozzi CR, J Am Chem Soc 2011, 133(44), 17570-17573; [PubMed: 21962173] i)Liu DS, Tangpeerachaikul A, Selvaraj R, Taylor MT, Fox JM, Ting AY, J Am Chem Soc 2012, 134(2), 792-795. [PubMed: 22176354]

[2]. Sletten E, Bertozzi C, Angew Chem Int Ed 2009, 48(38), 6974-6998.

[3]. a)Sievers EL, Senter PD, Annu Rev Med 2013, 64, 15-29; [PubMed: 23043493] b)Jaiswal JK, Mattoussi H, Mauro JM, Simon SM, Nat Biotechnol 2003, 21(1), 47-51; [PubMed: 12459736] c)Gao X, Cui Y, Levenson RM, Chung LW, Nie S, Nat Biotechnol 2004, 22(8), 969-976. [PubMed: 15258594]

[4]. Agarwal P, Bertozzi CR, Bioconjug Chem 2015, 26(2), 176-192. [PubMed: 25494884]

[5]. a)Stephanopoulos N, Francis M, Nat Chem Biol 2011, 7(12), 876-884; [PubMed: 22086289] b)Young TS, Schultz PG, J Biol Chem 2010, 285(15), 11039-11044; [PubMed: 20147747] c)Hallam TJ, Wold E, Wahl A, Smider VV, Mol Pharm 2015, 12(6), 1848-1862. [PubMed: 25898256]

[6]. Young DD, Schultz PG, ACS Chem Biol 2018, 13(4), 854-870. [PubMed: 29345901]

[7]. Lampkowski JS, Villa JK, Young TS, Young DD, Angew Chem Int Ed Engl 2015. 
[8]. Nimmo ZM, Halonski JF, Chatkewitz LE, Young DD, Bioorg Chem 2018, 76, 326-331. [PubMed: 29227916]

[9]. Travis CR, Mazur LE, Peairs EM, Gaunt GH, Young DD, Org Biomol Chem 2019, 17(13), 33963402. [PubMed: 30869108]

[10]. Maza J, Howard C, Vipani M, Travis C, Young DD, Bioorg Med Chem Lett 2017, 27(1), 30-33. [PubMed: 27894869]

[11]. Yamamoto Y, Curr Org. Chem. 2005, 9, 503.

[12]. a)Kotha S, Brahmachary E, Lahiri K, Eur. J. Org. Chem 2005, 22, 4741-4767;b)Young D, Deiters A, Angewandte Chemie-International Edition 2007, 46(27), 5187-5190; [PubMed: 17526034] c)McIver A, Young D, Deiters A, Chem Commun 2008(39), 4750-4752.

[13]. a)Wang YH, Huang SH, Lin TC, Tsai FY, Tetrahedron 2010, 66, 7136-7141;b)Wender PA, Love JA, Williams TJ, Synlett 2003, 9, 1295-1298;c)Li CJ, Chem Rev 2005, 105(8), 3095-3165. [PubMed: 16092827]

[14]. Young DD, Young T, Jahnz M, Ahmad I, Spraggon G, Schultz P, Biochemistry 2011, 50(11), 1894-1900. [PubMed: 21280675]

[15]. Schmid S, Zimmerman S, Krug HF, Sures B, Environ. Int. 2007, 33, 385-390. [PubMed: 17250893]

[16]. Satake Y, Abe S, Okazaki S, Ban N, Hikage T, Ueno T. Nakajima H, Suzuki A, Yamane T, Nishyama H, Wanatabe Y, Organomet 2007, 26, 4904-4908.

[17]. a)Li N, Lim R, Edwardraja S, Lin Q, J Am Chem Soc 2011, 133(39), 15316-15319; [PubMed: 21899368] b)Best M, Biochemistry 2009, 48(28), 6571-6584. [PubMed: 19485420] 
A

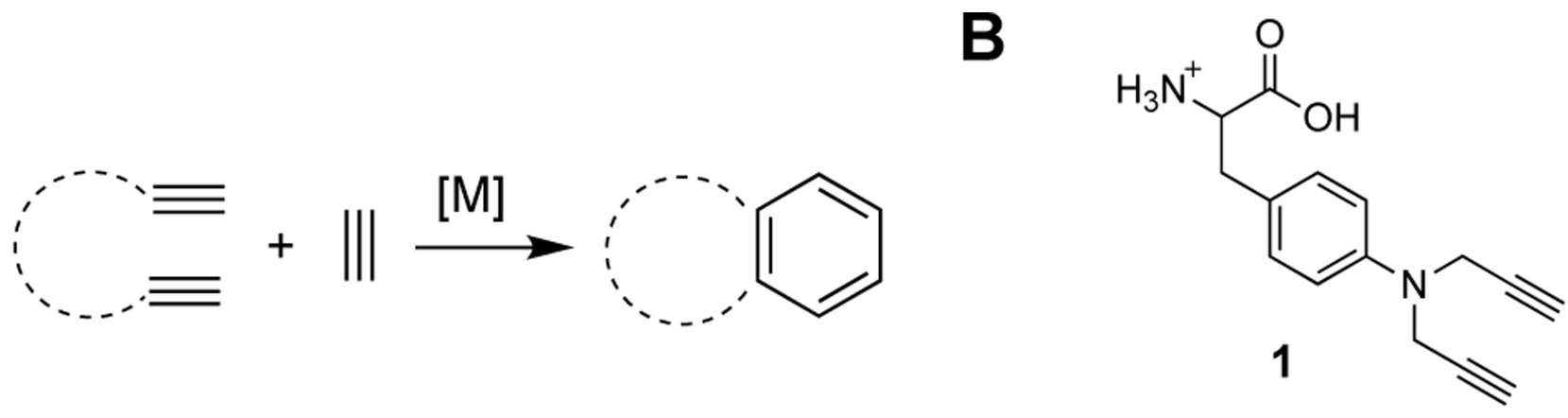

Lane

1

2

3

4

UAA

$$
p \operatorname{PrF}
$$

$p B r P r F$

pDPrAF

$27 \mathrm{kDa}$

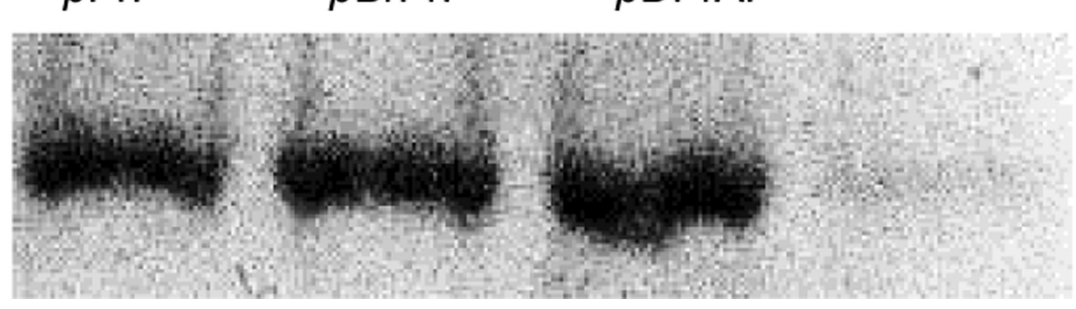

Figure 1.

Development of the components for a $[2+2+2]$ cyclotrimerization bioconjugation. A) Generic $[2+2+2]$ cycloaddition reaction. B) The synthesized $p \operatorname{DPrAF} U A A(\mathbf{1})$ to be employed in the bioconjugation. C) Incorporation of $\mathbf{1}$ into GFP at residue $151 \mathrm{using}$ the $p \mathrm{CNF}$ aaRS. This polyspecific synthetase has already been demonstrated to incorporate other UAAs ( $p$ PrF and $p \mathrm{BrPrF}$ ), and only small amounts of protein are detected in the absence of an UAA. 


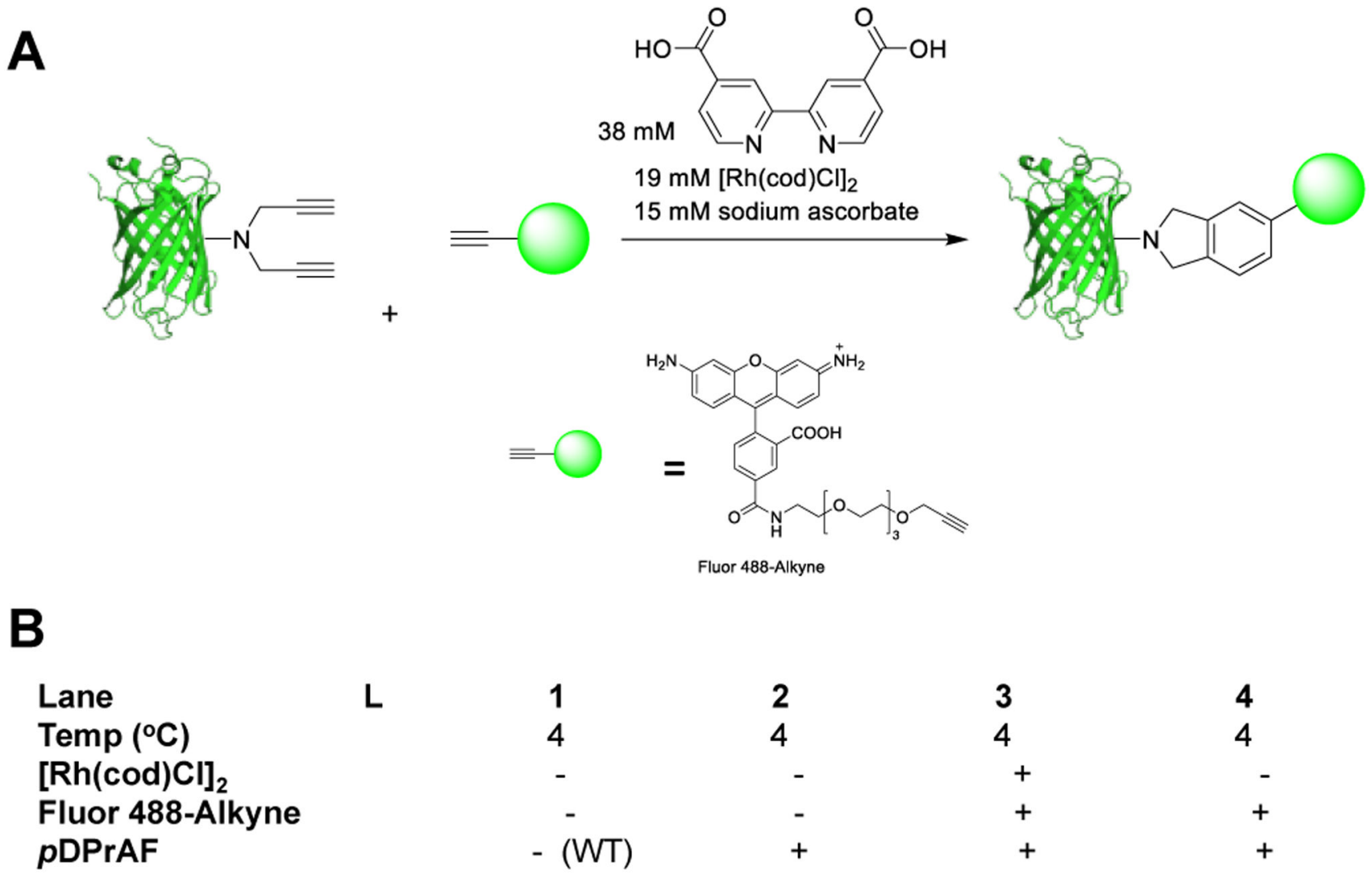

$27 \mathrm{kDa}$

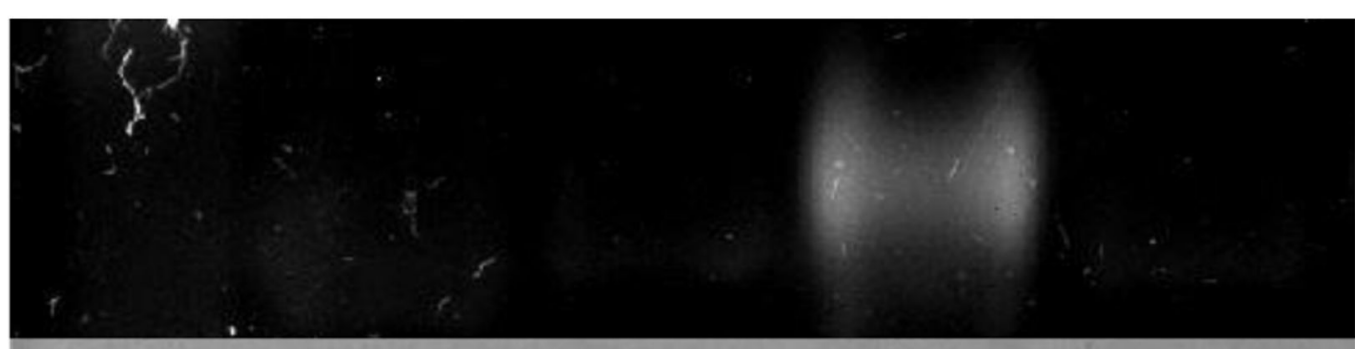

$27 \mathrm{kDa}$

Figure 2.

$[2+2+2]$ cycloaddition bioconjugation. A) Experimental proof-of-concept experiment linking the GFP-containing $p$ DPrAF with a Fluor 488-Alkyne label. Successful cycloaddition reaction yields an isoindole ring linkage. B) SDS-PAGE analysis of the successful bioconjugation. The gels were analyzed first for fluorescence (top gel) and then stained with Coomassie blue to visualize protein (bottom gel). Lane L: Protein ladder. Lane 1: Wild-type GFP protein containing Tyr at residue 151 demonstrating no fluorescent signal after denaturation of the protein. Lane 2: GFP containing 1 at residue 151 that was not 
subjected to reaction conditions. Lane 3: GFP containing 1 at residue 151 was reacted in the presence of both the Fluor 488-Alkyne and the rhodium system, affording the cycloaddition product and fluorescence due to the covalent linkage of the fluorophore to the protein. Lane 4: GFP containing 1 at residue 151 reacted in the presence of the Fluor 488-Alkyne but no rhodium, demonstrating that non-covalent association of the dye does not occur. 
A

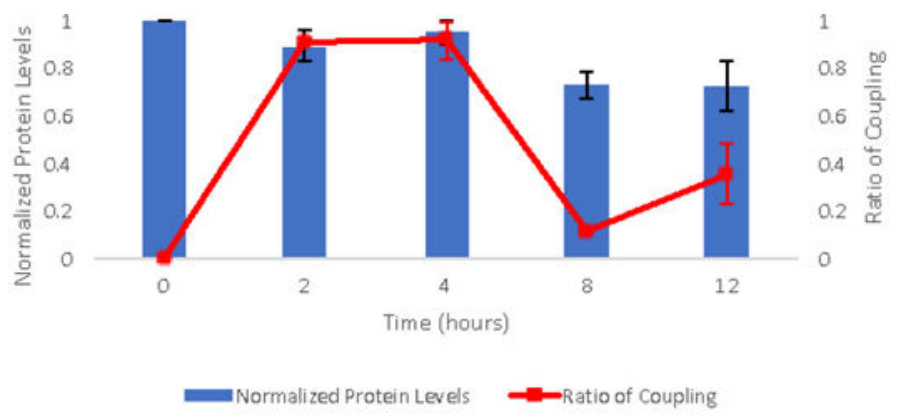

B

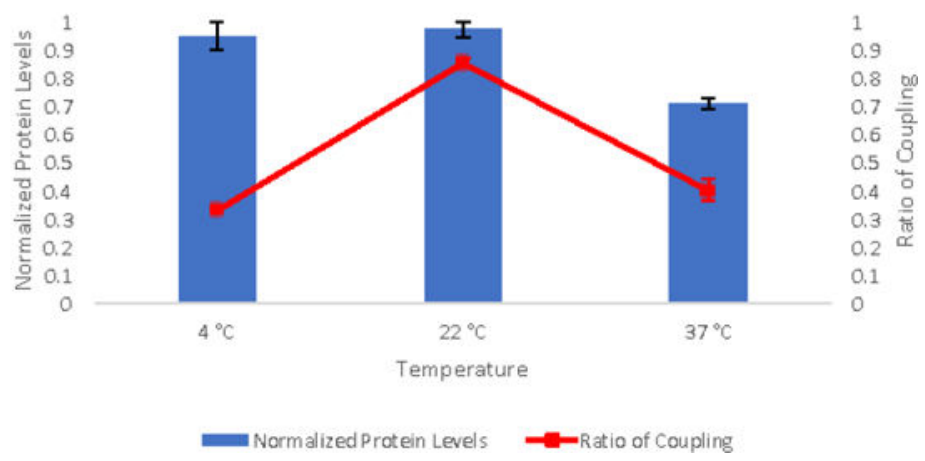

Figure 3.

Optimization of the novel $[2+2+2]$ cycloaddition bioconjugation. For each condition, error bars represent standard deviation with sample size $\mathrm{n}=3$. Ratio of coupling is a normalized calculation of the proportion of protein which is coupled to fluorophore. A) A time course to determine the optimal duration of this biological cyclotrimerization reaction was conducted. Reaction time of 2 hours leads to minimal protein degradation (bars) and maximal ratio of coupling (line) between the protein and the fluorophore. Generally, increasing protein degradation is observed with increasing reaction duration. B) A range of temperatures for the $[2+2+2]$ cycloaddition bioconjugation were tested. Conducting the reaction at $22{ }^{\circ} \mathrm{C}$ (room temperature) afforded the best ratio of coupling with very little protein degradation. Elevated temperature leads to increased protein degradation. 


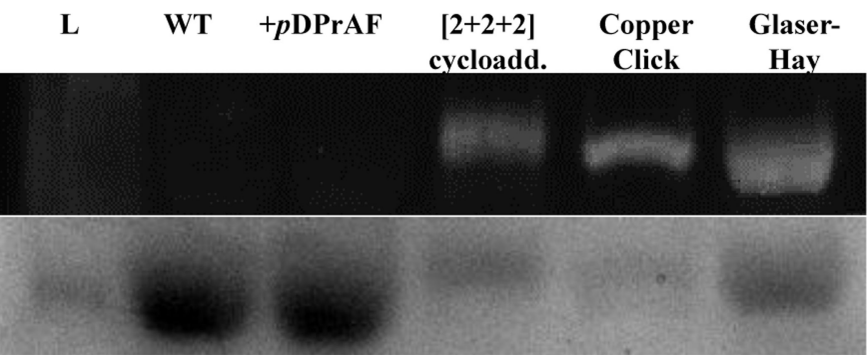

Figure 4.

Bioconjugation versatility of the $p$ DPAF UAA. SDS-PAGE analysis shows that the $p$ PrAF UAA 1 is capable of successfully participating in three unique bioconjugation reactions. The gel was analyzed first for fluorescence (top gel) and then stained with Coomassie blue to visualize protein (bottom gel). Lane L: Protein ladder. Lane 1: Wild-type GFP protein containing Tyr at residue 151 demonstrating no fluorescent signal after denaturation of the protein. Lane 2: GFP containing 1 at residue 151 that was not subjected to any reaction. Lane 3: GFP containing 1 at residue 151 was reacted with Fluor 488-Alkyne and the described rhodium system, affording the $[2+2+2]$ cycloaddition bioconjugation product and fluorescence due to the covalent linkage of the fluorophore to the protein. Lane 4: GFP containing 1 at residue 151 reacted with Fluor 488-Azide in the copper click reaction, affording the 1,3-dipolar cycloaddition bioconjugation product and fluorescence due to the covalent linkage of the fluorophore to the protein. Lane 5: GFP containing $\mathbf{1}$ at residue 151 reacted with Fluor 488-Alkyne in the Glaser-Hay reaction, affording the linear 1,3-diyne bioconjugation product and fluorescence due to the covalent linkage of the fluorophore to the protein. 